Supporting Information

\title{
MPC1001 and its Analogs, New Antitumor Agents from the Fungus Cladorrhinum Species
}

Hideyuki Onodera, ${ }^{*}{ }^{\dagger}$ Atsuhiro Hasegawa, ${ }^{\dagger}$ Noriko Tsumagari, $^{\dagger}{ }^{\text {Ryuichiro }}$ Nakai, ${ }^{\dagger}$ Tatsuhiro Ogawa, ${ }^{\dagger}$ and Yutaka Kanda ${ }^{*, \neq}$

${ }^{\dagger}$ Tokyo Research Laboratories, Kyowa Hakko Kogyo Co., Ltd., 3-6-6 Asahimachi, Machida, Tokyo 194-8533, Japan

${ }^{\ddagger}$ Pharmaceutical Research Institute, Kyowa Hakko Kogyo Co., Ltd., 1188 Shimotogari, Nagaizumi, Sunto, Shizuoka 411-8731, Japan

hideyuki.onodera@kyowa.co.jp 


\section{Table of Contents}

\section{Culture}

\section{Extraction and Purification}

Figure 1S. Purification of MPC1001 and its analogs (Scheme 1).

Figure 2S. Purification of MPC1001 and its analogs (Scheme 2).

\section{Chemicals}

Figure 3S. ${ }^{1} \mathrm{H}$ NMR spectrum of MPC1001 (1, $\left.\mathrm{CDCl}_{3}, 400 \mathrm{MHz}\right)$.

Figure $4 \mathrm{~S} .{ }^{13} \mathrm{C}$ NMR spectrum of MPC1001 $\left(\mathbf{1}, \mathrm{CDCl}_{3}, 100 \mathrm{MHz}\right)$.

Figure 5S. Comparison of CD spectral data of MPC1001 (1) to those of emestrin.

Figure 6S. ${ }^{1} \mathrm{H}$ NMR spectrum of MPC1001B (2, $\left.\mathrm{CDCl}_{3}, 400 \mathrm{MHz}\right)$.

Figure 7S. ${ }^{13} \mathrm{C}$ NMR spectrum of MPC1001B $\left(2, \mathrm{CDCl}_{3}, 100 \mathrm{MHz}\right)$.

Figure $8 \mathrm{~S}$. ${ }^{1} \mathrm{H}$ NMR spectrum of MPC1001C $\left(3, \mathrm{CDCl}_{3}, 500 \mathrm{MHz}\right)$.

Figure 9S. ${ }^{13} \mathrm{C}$ NMR spectrum of MPC1001C $\left(3, \mathrm{CDCl}_{3}, 125 \mathrm{MHz}\right)$.

Figure 10S. ${ }^{1} \mathrm{H}$ NMR spectrum of MPC1001D (4, $\left.\mathrm{CDCl}_{3}, 500 \mathrm{MHz}\right)$.

Figure 11S. ${ }^{13} \mathrm{C}$ NMR spectrum of MPC1001D (4, $\left.\mathrm{CDCl}_{3}, 125 \mathrm{MHz}\right)$.

Figure 12S. ${ }^{1} \mathrm{H}$ NMR spectrum of MPC1001E $\left(5, \mathrm{CDCl}_{3}, 500 \mathrm{MHz}\right)$.

Figure 13S. ${ }^{13} \mathrm{C}$ NMR spectrum of MPC1001E (5, $\left.\mathrm{CDCl}_{3}, 125 \mathrm{MHz}\right)$.

Figure 14S. ${ }^{1} \mathrm{H}$ NMR spectrum of $\mathrm{MPC} 1001 \mathrm{~F}\left(6, \mathrm{CDCl}_{3}, 400 \mathrm{MHz}\right)$.

Figure 15S. ${ }^{13} \mathrm{C}$ NMR spectrum of $\operatorname{MPC} 1001 \mathrm{~F}\left(6, \mathrm{CDCl}_{3}, 100 \mathrm{MHz}\right)$.

Figure 16S. ${ }^{1} \mathrm{H}$ NMR spectrum of MPC1001G (7, $\left.\mathrm{CDCl}_{3}, 500 \mathrm{MHz}\right)$.

Figure 17S. ${ }^{13} \mathrm{C}$ NMR spectrum of MPC1001G (7, $\left.\mathrm{CDCl}_{3}, 125 \mathrm{MHz}\right)$.

Figure 18S. ${ }^{1} \mathrm{H}$ NMR spectrum of $\mathrm{MPC} 1001 \mathrm{H}\left(\mathbf{8}, \mathrm{CDCl}_{3}, 400 \mathrm{MHz}\right)$.

Figure 19S. ${ }^{13} \mathrm{C}$ NMR spectrum of MPC1001H (8, $\left.\mathrm{CDCl}_{3}, 100 \mathrm{MHz}\right)$. 


\section{Culture}

The MPC1001 and its analogs producing fungal strain KY4922 was isolated from an Indonesian soil sample and identified as Cladorrhinum sp. KY4922 was cultured in the first seed medium consisting of glucose $10 \%$, dried mashed potato $3 \%$, and yeast extract $0.5 \%$ (pH6.5) for $120 \mathrm{hr}$ at $28^{\circ} \mathrm{C}$ on a rotary shaker. The first seed culture was added to Erlenmeyer flasks containing $50 \mathrm{ml}$ of the same medium. After incubation on a ratary shaker at $28^{\circ} \mathrm{C}$ for $10 \mathrm{hr}, 1.5$ $\mathrm{ml}$ of the sencond seed culture was innoculated into each of 100 Erlenmeyer flasks containing 50 $\mathrm{ml}$ of a production medium composed of soluble starch $5 \%$, dried yeast $1.5 \%, \mathrm{KH}_{2} \mathrm{PO}_{4} 0.05 \%$, $\mathrm{MgSO}_{4} \cdot \mathrm{H}_{2} \mathrm{O} 0.05 \%$, and $\mathrm{CaCO}_{3} 0.5 \%(\mathrm{pH} 7.0)$ and cultured on a rotary shaker (220 rpm) for 168 hr at $25^{\circ} \mathrm{C}$.

\section{Extraction and Purification}

The cultivated mycelium was extracted with $1.7 \mathrm{~L}$ of $\mathrm{MeOH}$. The extract was diluted with 2.3 L of water and then subjected to a Diaion HP-20 (250 ml, wet, Mitsubishi Chemical Corp.) column chromatography. The column was washed with $800 \mathrm{ml}$ of $70 \%$ aqueous $\mathrm{MeOH}$ and the active principles were eluted with $1 \mathrm{~L}$ of $\mathrm{MeOH}$-aceton (70:30) yielded $3.84 \mathrm{~g}$ of yellow oil. Further purification steps were summarized in Figure 1S and 2S. 


\section{Scheme 1}

Culture Broth $5 \mathrm{~L}$ (300 mL Erlenmeyer flasks x 100)

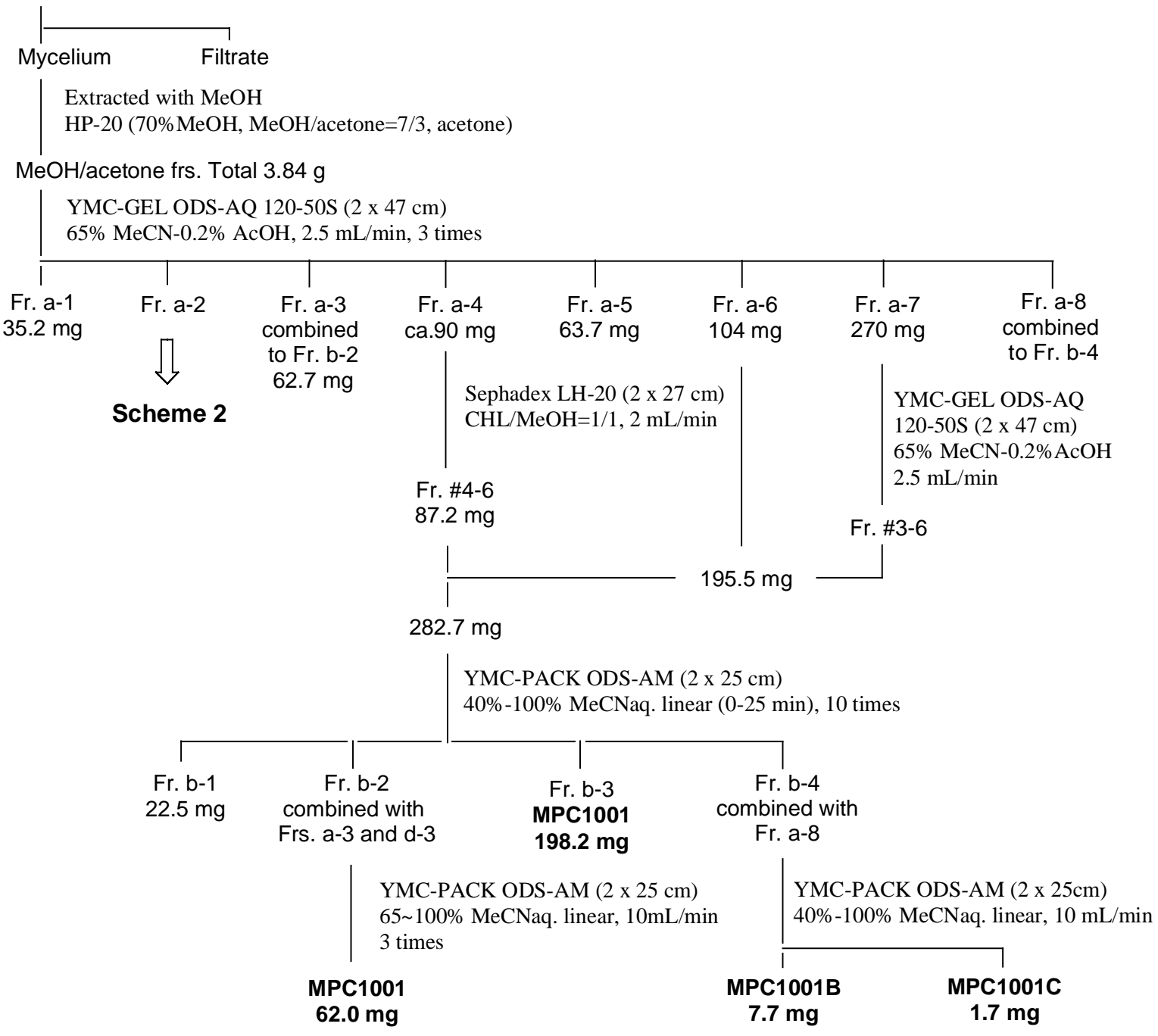

Figure 1S. Purification of MPC1001 and its analogs (Scheme 1). 


\section{Scheme 2}

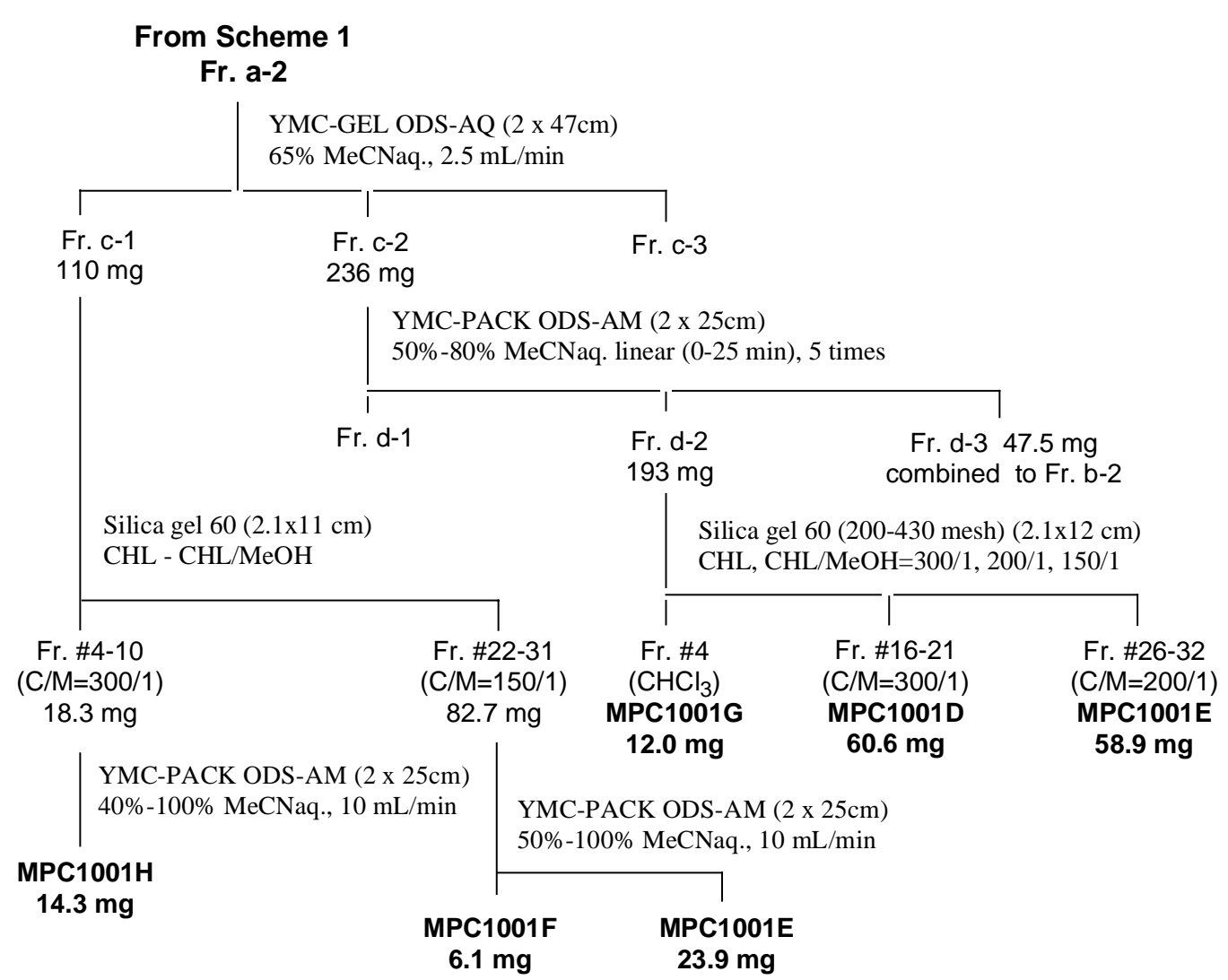

Figure 2S. Purification of MPC1001 and its analogs (Scheme 2). 


\section{Chemicals}

General Methods. ${ }^{1} \mathrm{H}$ and ${ }^{13} \mathrm{C}$ NMR spectra were recorded on Bruker DMX-500 or JEOL JNM- $\alpha 400$ spectrometer. Chemical shifts were reported in ppm using the residual solvent as an internal standard (chloroform, 7.26 and $77.05 \mathrm{ppm}$ for ${ }^{1} \mathrm{H}$ and ${ }^{13} \mathrm{C}$ NMR, respectively). NMR data are reported as follows: chemical shifts, integration, multiplicity $(\mathrm{s}=$ singlet, $\mathrm{d}=$ doublet, $\mathrm{t}=$ triplet, $\mathrm{q}=$ quartet, $\mathrm{m}=$ multiplet, $\mathrm{br}=$ broad), coupling constant, and position. FAB-MS spectra were obtained with JEOL JMS-HX/HX110A spectrometer using $m$-nitrobenzyl alcohol (NBA) as a matrix. IR spectra were recorded on JEOL JIR-RFX3001 or JASCO IR-870 spectrometer. UV spectra were measured in $\mathrm{MeOH}$ on Shimadzu UV-1600PC or UV-2200 spectrometer. Optical rotations were measured in $\mathrm{MeOH}$ or $\mathrm{CHCl}_{3}$ at 20 or $28^{\circ} \mathrm{C}$ on a JASCO DIP-370 polarimeter. Melting points were determined using Yanagimoto micro melting point apparatus and are uncorrected. HPLC analysis was performed on a Develosil ODS-HG-3 column (4.6 i.d. $\times 50 \mathrm{~mm}$, Nomura Chemical Co., LTD, Seto, Japan) with aqueous 20-100\% MeCN gradient elution. Peaks were monitored with a Waters 996 photodiode array detector.

MPC1001 (1). ${ }^{1} \mathrm{H}$ NMR $\left(\mathrm{CDCl}_{3}, 400 \mathrm{MHz}\right) \delta 7.76(1 \mathrm{H}, \mathrm{dd}, 8.5,2.1, \mathrm{H}-6$ ') 7.66 (1H, d, 2.2, H-6”), 7.63 (1H, d, 2.1, H-2'), 7.10 (1H, dd, 8.4, 2.2, H-4”), 7.05 (1H, d, 8.5, H-5'), 6.92 (1H, d, 8.4, H-3”), 6.91 (1H, d, 2.7, H-10), 6.32 (1H, dd, 8.4, 2.4, H-8), 5.91 (1H, dd, 7.7, 2.7, H-5a), 5.43 (1H, br.d, 12.3, H-7”), 5.21 (1H, br.s, 11-OH), 4.95 (1H, dd, 8.4, 2.4, H-7), 4.92 (1H, s, H-11), 4.79 (1H, ddd, 7.7, 2.4, 2.4, H-6), 4.75 (1H, br.d, 12.3, 7'-OH), 3.99 (3H, s, 4'-OCH ${ }_{3}$ ), 3.94 (3H, s, 2"- $\left.\mathrm{OCH}_{3}\right), 3.41\left(3 \mathrm{H}, \mathrm{s}, 2-\mathrm{CH}_{3}\right) ;{ }^{13} \mathrm{C} \mathrm{NMR}\left(\mathrm{CDCl}_{3}, 100 \mathrm{MHz}\right) \delta 166.7$ (C-1), $165.1\left(\mathrm{C}-7^{\prime}\right), 163.4$ (C-4), 154.6 (C-4'), 151.8 (C-2”), 147.0 (C-1”), 145.1 (C-3'), 143.3 (C-10), 137.7 (C-8), 126.8 (C-5”), 125.6 (C-6'), 124.2 (C-4”), 122.3 (C-1'), 122.2 (C-2'), 119.8 (C-6”), 112.2 (C-5'), 111.4 (C-10a), 111.0 (C-3”), 107.3 (C-7), 78.8 (C-3), 76.6 (C-11), 75.3 (C-6), 74.8 (C-7”), 73.8 (C-11a), 61.1 (C-5a), $56.2\left(4^{\prime}-\mathrm{OCH}_{3}\right), 56.0\left(2\right.$ '- $\left.-\mathrm{OCH}_{3}\right), 27.9\left(2-\mathrm{CH}_{3}\right)$; white powder; mp 181-184 ${ }^{\circ} \mathrm{C}$; $[\alpha]^{20}{ }_{\mathrm{D}}+117^{\circ}\left(c\right.$ 0.3, MeOH); HRFAB-MS found $m / z 611.0802[\mathrm{M}-\mathrm{H}]^{+}$, calcd $m / z 611.0794$ for $\mathrm{C}_{28} \mathrm{H}_{23} \mathrm{~N}_{2} \mathrm{O}_{10} \mathrm{~S}_{2}$; FAB-MS m/z $635[\mathrm{M}+\mathrm{Na}]^{+}, \mathrm{m} / z 613[\mathrm{M}+\mathrm{H}]^{+}, \mathrm{m} / z 548\left[\mathrm{M}-\mathrm{S}_{2}\right]^{+}, \mathrm{m} / z 531$ $\left[\mathrm{M}-\mathrm{S}_{2}-\mathrm{H}_{2} \mathrm{O}+\mathrm{H}\right]^{+}, m / z 611[\mathrm{M}-\mathrm{H}]^{-} ; \mathrm{UV} \lambda_{\max }^{\mathrm{MeOH}}$ (ع) 205 (38,000), $263(14,000), 283(8,000) \mathrm{nm}$;

IR $v_{\max }{ }^{\mathrm{KBr}} 3442,1716,1684,1668,1614,1515,1346,1271,1200,1174,1136,1122,1051,1024$, $891,822,762 \mathrm{~cm}^{-1} ; \mathrm{R}_{\mathrm{f}}$ value on TLC ( $n$-hexane-acetone, 1:1) $=0.45$; Soluble in methanol, acetonitrile, acetone, ethyl acetate, chloroform, dimethyl sulfoxide.

MPC1001B (2). ${ }^{1} \mathrm{H}$ NMR (CDCl 3 , $\left.400 \mathrm{MHz}\right) \delta 8.04$ (1H, d, 2.2, H-6”), 7.66 (1H, dd, 8.5, 2.0, H-6'), 7.63 (1H, d, 2.0, H-2'), 7.15 (1H, dd, 8.4, 2.2, H-4”), 7.01 (1H, d, 8.5, H-5'), 6.88 (1H, d, 
8.4, H-3”), 6.63 (1H, ddd, 2.2, 2.2, 2.2, H-10), 6.32 (1H, dd, 8.3, 2.2, H-8), 5.44 (1H, d, 12.3, H-7”), 5.40 (1H, dddd, 8.8, 2.2, 2.0, 1.1, H-5a), 5.12 (1H, d, 12.3, 7”-OH), 4.99 (1H, ddd, 8.8, 2.2, 1.7, H-6), $4.93(1 \mathrm{H}, \mathrm{dd}, 8.3,1.7, \mathrm{H}-7), 4.16(1 \mathrm{H}, \mathrm{ddd}, 18.1,2.2,1.1, \mathrm{H}-11 \beta), 4.01(3 \mathrm{H}, \mathrm{s}$, 4'- $\left.\mathrm{OCH}_{3}\right), 3.86\left(3 \mathrm{H}, \mathrm{s}, 2\right.$ '- $\left.-\mathrm{OCH}_{3}\right), 3.48\left(3 \mathrm{H}, \mathrm{s}, 2-\mathrm{CH}_{3}\right), 3.02(1 \mathrm{H}, \mathrm{ddd}, 18.1,2.2,2.0, \mathrm{H}-11 \alpha) ;{ }^{13} \mathrm{C}$

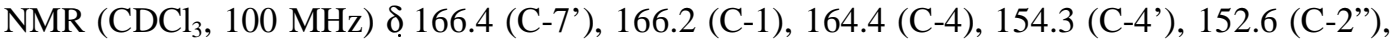
146.2 (C-1”), 146.0 (C-3’), 140.6 (C-8), 139.4 (C-10), 127.1 (C-5”), 125.6 (C-4”), 125.4 (C-6'), 122.8 (C-6”), 122.8 (C-1'), 119.3 (C-2'), 112.8 (C-10a), 112.2 (C-5'), 111.0 (C-3”), 105.6 (C-7), 78.4 (C-3), 75.3 (C-7”), 73.0 (C-6), 72.5 (C-11a), 62.3 (C-5a), 56.4 (4'- $\mathrm{OCH}_{3}$ ), 56.0 (2”- $\mathrm{OCH}_{3}$ ), 34.9 (C-11), $28.3\left(2-\mathrm{CH}_{3}\right)$; white powder; $\mathrm{mp} 171-172{ }^{\circ} \mathrm{C} ;[\alpha]_{\mathrm{D}}^{28}+242.6^{\circ}\left(c 0.23, \mathrm{CHCl}_{3}\right)$; HRFAB-MS found $m / z 595.0850[\mathrm{M}-\mathrm{H}]^{+}$, calcd $m / z 595.0845$ for $\mathrm{C}_{28} \mathrm{H}_{23} \mathrm{~N}_{2} \mathrm{O}_{9} \mathrm{~S}_{2}$; FAB-MS $m / z$

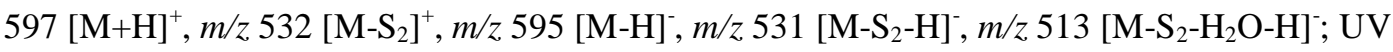
$\lambda_{\max }{ }^{\mathrm{MeOH}}(\varepsilon) 257$ (19,700), $284(8,900) \mathrm{nm}$; IR $v_{\max }{ }^{\mathrm{KBr}} 3474,2940,1686,1611,1577,1513,1457$, 1440, 1412, 1350, 1268, 1195, 1172, 1135, 1122, 1055, 1024, 990, 965, 907, 818, $762 \mathrm{~cm}^{-1}$; Soluble in chloroform, dimethyl sulfoxide.

MPC1001C (3). ${ }^{1} \mathrm{H}$ NMR $\left(\mathrm{CDCl}_{3}, 500 \mathrm{MHz}\right) \delta 7.73(1 \mathrm{H}, \mathrm{dd}, 8.5,2.0, \mathrm{H}-6$ ') $7.63(1 \mathrm{H}, \mathrm{d}, 2.1$, H-6"), 7.60 (1H, d, 2.0, H-2'), 7.10 (1H, dd, 8.3, 2.1, H-4”), 7.03 (1H, d, 8.5, H-5'), 6.91 (1H, d, 8.3, H-3”), 6.90 (1H, d, 2.4, H-10), 6.31 (1H, dd, 8.4, 2.5, H-8), 5.87 (1H, dd, 7.7, 2.4, H-5a), 5.21 (1H, br.s, 11-OH), 4.94 (1H, dd, 8.4, 2.1, H-7), 4.93 (1H, s, H-11), 4.81 (1H, ddd, 7.7, 2.5, 2.1, H-6), 3.98 (3H, s, 4'-OCH $), 3.91$ (3H, s, 2"'-OCH 3 ), 3.83 (1H, d, 13.3, H-7’ $\beta), 3.45$ (1H, d, 13.3, H-7” $\alpha$ ), 3.21 (3H, s, 2-CH $\left.{ }_{3}\right){ }^{13}{ }^{C}$ NMR ( $\left.\mathrm{CDCl}_{3}, 125 \mathrm{MHz}\right) \delta 166.8$ (C-1), 165.3 (C-7'), 162.5 (C-4), 154.3 (C-4'), 151.0 (C-2”), 146.0 (C-1”), 145.2 (C-3'), 143.2 (C-10), 137.7 (C-8), 126.4 (C-4”), 125.4 (C-6'), 124.7 (C-6”), 123.4 (C-5”), 122.5 (C-1'), 121.8 (C-2'), 112.0 (C-5'), 111.8 (C-10a), 111.5 (C-3”), 107.6 (C-7), 79.2 (C-3), 76.8 (C-11), 75.4 (C-6), 74.0 (C-11a), 61.0 (C-5a), $56.1\left(4^{\prime}-\mathrm{OCH}_{3}\right), 55.9\left(2\right.$ '- $\left.-\mathrm{OCH}_{3}\right), 36.2\left(\mathrm{C}-7\right.$ ”), $27.9\left(2-\mathrm{CH}_{3}\right)$; white powder; mp 167-168 ${ }^{\circ} \mathrm{C}$; $[\alpha]^{28}{ }_{\mathrm{D}}+188.7^{\circ}\left(\mathrm{c} 0.13, \mathrm{CHCl}_{3}\right)$; HRFAB-MS found $\mathrm{m} / z 595.0858[\mathrm{M}-\mathrm{H}]^{+}$, calcd $\mathrm{m} / z 595.0845$ for $\mathrm{C}_{28} \mathrm{H}_{23} \mathrm{~N}_{2} \mathrm{O}_{9} \mathrm{~S}_{2} ; \mathrm{FAB}-\mathrm{MS} m / z 597[\mathrm{M}+\mathrm{H}]^{+}, m / z 532\left[\mathrm{M}-\mathrm{S}_{2}\right]^{+}, m / z 515\left[\mathrm{M}-\mathrm{S}_{2}-\mathrm{H}_{2} \mathrm{O}+\mathrm{H}\right]^{+}, m / z 596$ [M]; UV $\lambda_{\max }{ }^{\mathrm{MeOH}}(\varepsilon) 262(13,400), 284(6,700) \mathrm{nm}$; IR $v_{\max }{ }^{\mathrm{KBr}} 3470,1712,1688,1611,1577$, 1513, 1459, 1440, 1413, 1351, 1268, 1219, 1195, 1172, 1135, 1122, 1108, 1091, 1055, 1024, 990, $969,904,818,761 \mathrm{~cm}^{-1}$; Soluble in chloroform, dimethyl sulfoxide.

MPC1001D (4). ${ }^{1} \mathrm{H}$ NMR (CDCl 3 , $\left.500 \mathrm{MHz}\right) \delta 8.35$ (1H, d, 2.3, H-6”), 7.98 (1H, d, 2.0, H-2'), 7.73 (1H, dd, 8.5, 2.0, H-6'), 7.03 (1H, dd, 8.4, 2.3, H-4”), 7.02 (1H, d, 8.5, H-5'), 6.83 (1H, d, 2.4, H-10), 6.83 (1H, d, 8.4, H-3”), 6.35 (1H, dd, 8.0, 2.3, H-8), 5.39 (1H, dd, 8.2, 2.4, H-5a), 5.28 (1H, 
d, 12.5, H-7”), 5.26 (1H, ddd, 8.2, 2.6, 2.3, H-6), 5.02 (1H, dd, 8.0, 2.6, H-7), 4.79 (1H, d, 2.0, H-11), $4.30(1 \mathrm{H}, \mathrm{d}, 12.5,7$ '- $\mathrm{OH}), 4.03\left(3 \mathrm{H}, \mathrm{s}, 4^{\prime}-\mathrm{OCH}_{3}\right), 3.86\left(3 \mathrm{H}, \mathrm{s}, 2\right.$ '- $\left.-\mathrm{OCH}_{3}\right), 3.56(3 \mathrm{H}, \mathrm{s}$, 2- $\left.\mathrm{CH}_{3}\right), 3.52(1 \mathrm{H}, \mathrm{d}, 2.0,11-\mathrm{OH}) ;{ }^{13} \mathrm{C} \mathrm{NMR}\left(\mathrm{CDCl}_{3}, 125 \mathrm{MHz}\right) \delta 168.2$ (C-1), 166.4 (C-7'), 165.3 (C-4), 154.7 (C-4'), 152.3 (C-2”), 146.3 (C-3'), 145.7 (C-1”), 143.0 (C-10), 138.6 (C-8), 128.7 (C-4”), 127.1 (C-5”), 125.9 (C-6'), 125.6 (C-6”), 122.4 (C-1'), 119.6 (C-2'), 112.2 (C-5'), 110.8 (C-3”), 110.0 (C-7), 108.0 (C-10a), 83.4 (C-11a), 79.8 (C-11), 78.1 (C-3), 76.6 (C-7”), 74.9 (C-6), 59.0 (C-5a), $56.4\left(4^{\prime}-\mathrm{OCH}_{3}\right), 56.1\left(2\right.$ '- $\left.-\mathrm{OCH}_{3}\right), 28.9\left(2-\mathrm{CH}_{3}\right)$; white powder; mp $188-190{ }^{\circ} \mathrm{C} ;[\alpha]^{28}{ }_{\mathrm{D}}+174.2^{\circ}\left(\mathrm{c} 0.66, \mathrm{CHCl}_{3}\right)$; HRFAB-MS found $\mathrm{m} / z 643.0516[\mathrm{M}-\mathrm{H}]^{+}$, calcd $\mathrm{m} / \mathrm{z}$ 643.0514 for $\mathrm{C}_{28} \mathrm{H}_{23} \mathrm{~N}_{2} \mathrm{O}_{10} \mathrm{~S}_{3} ; \mathrm{FAB}-\mathrm{MS} m / z 644[\mathrm{M}]^{+}, m / z 627\left[\mathrm{M}-\mathrm{H}_{2} \mathrm{O}+\mathrm{H}\right]^{+}, m / z 548\left[\mathrm{M}-\mathrm{S}_{3}\right]^{+}, m / z$

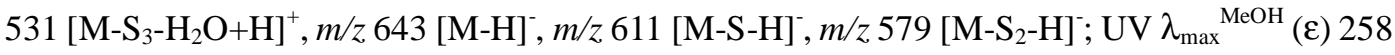
(19,700), 284 (7,900) nm; IR $v_{\max }{ }^{\mathrm{KBr}} 3484,2958,1681,1610,1577,1513,1462,1441,1409,1358$, $1268,1195,1172,1135,1122,1102,1056,1026,900,820,800,762 \mathrm{~cm}^{-1}$; Soluble in methanol, chloroform, ethyl acetate, dimethyl sulfoxide.

MPC1001E (5). ${ }^{1} \mathrm{H} \mathrm{NMR}\left(\mathrm{CDCl}_{3}, 500 \mathrm{MHz}\right) \delta 9.81$ (1H, s, H-7”), 8.03 (1H, dd, 8.6, 2.1, H-6'), 7.71 (1H, d, 2.1, H-2'), 7.64 (1H, dd, 8.4, 1.9, H-4”), 7.40 (1H, d, 1.9, H-6”), 7.11 (1H, d, 8.4, H-3”), 7.08 (1H, d, 8.6, H-5'), 6.84 (1H, d, 2.4, H-10), 6.29 (1H, dd, 8.1, 2.3, H-8), 5.43 (1H, dd, 8.4, 2.4, H-5a), 5.28 (1H, ddd, 8.4, 2.3, 2.1, H-6), 4.97 (1H, s, H-3), 4.87 (1H, dd, 8.1, 2.1, H-7), 4.87 (1H, s, H-11), 3.98 (3H, s, 2'- $\left.-\mathrm{OCH}_{3}\right), 3.93$ (3H, s, 4'- $\left.-\mathrm{OCH}_{3}\right), 3.21$ (3H, br.s, 11-OH), 3.03 (1H, s, 2-CH $\left.\mathrm{CH}_{3}\right){ }^{13} \mathrm{C}^{\mathrm{NMR}}\left(\mathrm{CDCl}_{3}, 125 \mathrm{MHz}\right) \delta 190.8$ (C-7’), 167.2 (C-1), 165.6 (C-7'), 163.3 (C-4), 156.0 (C-2”), 155.0 (C-4'), 146.5 (C-1”), 144.9 (C-3'), 143.0 (C-10), 139.1 (C-8), 130.2 (C-5”), 128.5 (C-4”), 128.0 (C-6’), 122.6 (C-1'), 121.0 (C-2'), 118.4 (C-6”), 112.0 (C-3”), 111.8 (C-5'), 110.3 (C-10a), 107.8 (C-7), 80.0 (C-11a), 78.2 (C-11), 71.8 (C-6), 67.5 (C-3), 60.0 (C-5a), $56.4\left(2^{\prime \prime}-\mathrm{OCH}_{3}\right), 56.2\left(4^{\prime}-\mathrm{OCH}_{3}\right), 32.5\left(2-\mathrm{CH}_{3}\right)$; white powder; mp 166-167 ${ }^{\circ} \mathrm{C} ;[\alpha]^{28}{ }_{\mathrm{D}}-128.4^{\circ}(c$ 0.76, $\mathrm{CHCl}_{3}$ ); HRFAB-MS found $m / z 676.0339[\mathrm{M}]^{-}$, calcd $m / z 676.0313$ for $\mathrm{C}_{28} \mathrm{H}_{24} \mathrm{~N}_{2} \mathrm{O}_{10} \mathrm{~S}_{4}$;

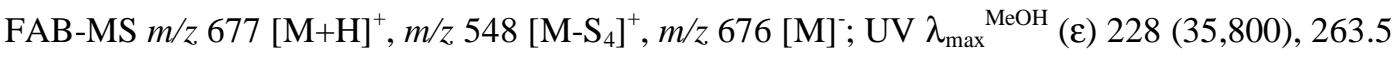
$(22,000) \mathrm{nm} ; \mathrm{IR} v_{\max }{ }^{\mathrm{KBr}} 3428,2936,1686,1603,1573,1509,1451,1431,1411,1390,1334,1268$, 1221, 1195, 1176, 1130, 1116, 1060, 1020, 907, 812, $761 \mathrm{~cm}^{-1}$; Soluble in chloroform, dimethyl sulfoxide.

MPC1001F (6). ${ }^{1} \mathrm{H}$ NMR $\left(\mathrm{CDCl}_{3}, 400 \mathrm{MHz}\right) \delta 9.81(1 \mathrm{H}, \mathrm{s}, \mathrm{H}-7$ '”), $8.02(1 \mathrm{H}, \mathrm{dd}, 8.6,2.2, \mathrm{H}-6$ '), $7.64(1 \mathrm{H}, \mathrm{dd}, 8.5,2.0, \mathrm{H}-4$ ”), 7.61 (1H, d, 2.2, H-2'), 7.33 (1H, d, 2.0, H-6”), 7.10 (1H, d, 8.5, H-3”), 7.09 (1H, d, 8.6, H-5'), 6.89 (1H, d, 2.4, H-10), 6.35 (1H, dd, 8.2 2. 2.4, H-8), 5.85 (1H, ddd, 8.1, 2.4, 2.2, H-6), 5.39 (1H, dd, 8.1, 2.4, H-5a), 4.91 (1H, dd, 8.2, 2.2, H-7), 4.89 (1H, s, H-11), 
3.98 (3H, s, 2"- $\left.-\mathrm{OCH}_{3}\right), 3.91$ (3H, s, 4'- $\left.-\mathrm{OCH}_{3}\right), 3.30$ (3H, s, 2- $\left.\mathrm{CH}_{3}\right), 2.75$ (1H, br.s, 11-OH), 2.06 (3H, s, 11a-SCH $)_{3}$ ppm; ${ }^{13} \mathrm{C} \mathrm{NMR}\left(\mathrm{CDCl}_{3}, 100 \mathrm{MHz}\right) \delta 190.7$ (C-7”), 166.3 (C-1), 165.2 (C-7'), 156.6 (C-3), 155.7 (C-2”), 155.1 (C-4'), 152.5 (C-4), 146.5 (C-1”), 144.8 (C-3’), 142.3 (C-10), 139.3 (C-8), 130.2 (C-5”), 128.1 (C-6'), 127.8 (C-4”), 122.1 (C-1'), 121.1 (C-2'), 118.2 (C-6”), 112.3 (C-5’), 112.1 (C-3”), 111.0 (C-10a), 107.7 (C-7), 78.1 (C-11), 76.3 (C-11a), 72.3 (C-6), 60.3 (C-5a), $56.4\left(2\right.$ '- $\left.-\mathrm{OCH}_{3}\right), 56.2\left(4^{\prime}-\mathrm{OCH}_{3}\right), 27.7\left(2-\mathrm{CH}_{3}\right), 13.0\left(11 \mathrm{a}-\mathrm{SCH}_{3}\right)$; white powder; $\mathrm{mp}$ $138-139^{\circ} \mathrm{C} ;[\alpha]^{28}{ }_{\mathrm{D}}+19.7^{\circ}\left(c 0.12, \mathrm{CHCl}_{3}\right)$; HRFAB-MS found $\mathrm{m} / \mathrm{z} 611.1334[\mathrm{M}+\mathrm{H}]^{+}$, calcd $\mathrm{m} / \mathrm{z}$

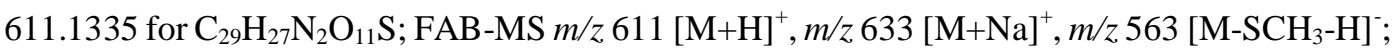
UV $\lambda_{\max }{ }^{\mathrm{MeOH}}(\varepsilon) 262.5(21,600) \mathrm{nm}$; IR $v_{\max }{ }^{\mathrm{KBr}} 3452,1708,1692,1604,1511,1431,1406,1336$, 1316, 1271, 1240, 1223, 1195, 1175, 1130, 1119, 1020, $762 \mathrm{~cm}^{-1}$; Soluble in chloroform, dimethyl sulfoxide.

MPC1001G (7). ${ }^{1} \mathrm{H}$ NMR $\left(\mathrm{CDCl}_{3}, 500 \mathrm{MHz}\right) \delta 9.80$ (1H, s, H-7”), 8.01 (1H, dd, 8.6, 2.1, H-6'), 7.62 (1H, dd, 8.4, 1.9, H-4”), 7.61 (1H, d, 2.1, H-2'), 7.28 (1H, d, 1.9, H-6”), 7.09 (1H, d, 8.4, H-3”), 7.07 (1H, d, 8.6, H-5'), 7.04 (1H, d, 2.4, H-10), 6.83 (1H, s, H-11), 6.41 (1H, dd, 8.4, 2.2, H-8), 5.61 (1H, dd, 8.2, 2.4, H-5a), 5.43 (1H, ddd, 8.2, 2.2, 2.0, H-6), 5.03 (1H, dd, 8.4, 2.0, H-7), 3.98 (3H, s, 2"'-OCH $), 3.91$ (3H, s, 4'- $\left.-\mathrm{OCH}_{3}\right), 3.65\left(3 \mathrm{H}, \mathrm{s}, 2-\mathrm{CH}_{3}\right),{ }^{13} \mathrm{C} \mathrm{NMR}\left(\mathrm{CDCl}_{3}, 125\right.$ MHz) $\delta 190.7$ (C-7’), 186.9 (C-3), 165.6 (C-7'), 155.5 (C-2”), 155.3 (C-4'), 154.2 (C-1), 148.1 (C-4), 146.8 (C-1”), 144.4 (C-3'), 141.3 (C-10), 140.1 (C-8), 131.5 (C-11a), 130.1 (C-5”), 128.4 (C-6'), 127.5 (C-4”), 122.1 (C-1'), 122.0 (C-11), 121.7 (C-2'), 119.3 (C-10a), 117.6 (C-6”), 112.1 (C-5'), 112.0 (C-3”), 108.0 (C-7), 69.4 (C-6), 64.4 (C-5a), 56.4 (2”- $\left.\mathrm{OCH}_{3}\right), 56.2$ (4'-OCH $\mathrm{OCH}_{3}, 34.7$ (2- $\left.\mathrm{CH}_{3}\right)$; dark orange powder; mp $117-119{ }^{\circ} \mathrm{C} ;[\alpha]^{28}{ }_{\mathrm{D}}-578.8^{\circ}\left(c 0.17, \mathrm{CHCl}_{3}\right)$; HRFAB-MS found $m / z 563.1126[\mathrm{M}+\mathrm{H}]^{+}$, calcd $m / z 563.1124$ for $\mathrm{C}_{28} \mathrm{H}_{23} \mathrm{~N}_{2} \mathrm{O}_{9} \mathrm{~S}$; FAB-MS $m / z 563[\mathrm{M}+\mathrm{H}]^{+}$, $m / z 531[\mathrm{M}-\mathrm{S}]^{+}, m / z 562[\mathrm{M}]^{-}$; UV $\lambda_{\max }{ }^{\mathrm{MeOH}}$ (ع) $263.5(23,300), 341 \mathrm{sh}(7,100), 415.5(6,400) \mathrm{nm}$; IR $v_{\max }{ }^{K B r} 3452,2936,1704,1689,1634,1596,1509,1429,1398,1300,1267,1224,1177,1140$, $1116,1019,815,760,750,737 \mathrm{~cm}^{-1}$; Soluble in chloroform, dimethyl sulfoxide.

MPC1001H (8). ${ }^{1} \mathrm{H}$ NMR ( $\left.\mathrm{CDCl}_{3}, 400 \mathrm{MHz}\right) \delta 9.81$ (1H, s, H-7”), 8.02 (1H, dd, 8.6, 2.2, H-6'), 7.63 (1H, dd, 8.5, 1.9, H-4"), 7.60 (1H, d, 1.9, H-2'), 7.31 (1H, d, 1.9, H-6”), 7.10 (1H, d, 8.5, H-3”), 7.07 (1H, d, 8.6, H-5'), 6.99 (1H, d, 2.4, H-10), 6.85 (1H, s, H-11), 6.39 (1H, dd, 8.4, 2.2, H-8), 5.54 (1H, dd, 8.2, 2.4, H-5a), 5.42 (1H, ddd, 8.2, 2.2, 1.7, H-6), 4.98 (1H, dd, 8.4, 1.7, $\mathrm{H}-7), 3.97$ (3H, s, 2"'-OCH $), 3.91$ (3H, s, 4'- $\left.\mathrm{OCH}_{3}\right), 3.30\left(3 \mathrm{H}, \mathrm{s}, 2-\mathrm{CH}_{3}\right),{ }^{13} \mathrm{C} \mathrm{NMR}\left(\mathrm{CDCl}_{3}, 100\right.$ MHz) $\delta 190.7$ (C-7”), 165.5 (C-7'), 157.0 (C-3), 156.0 (C-1), 155.6 (C-2”), 155.2 (C-4'), 149.2 (C-4), 146.5 (C-1”), 144.7 (C-3'), 141.1 (C-10), 140.1 (C-8), 131.1 (C-11a), 130.1 (C-5”), 128.2 
(C-6'), 127.5 (C-4”), 122.1 (C-11), 122.0 (C-1'), 121.2 (C-2'), 118.9 (C-10a), 118.1 (C-6”), 112.2 (C-5'), 112.1 (C-3”), 107.8 (C-7), 69.2 (C-6), 63.8 (C-5a), 56.3 (2”- $\left.-\mathrm{OCH}_{3}\right), 56.2\left(4\right.$ '- $\left.\mathrm{OCH}_{3}\right), 27.4$ $\left(2-\mathrm{CH}_{3}\right)$; pale yellow powder; mp $127-128^{\circ} \mathrm{C}$; $[\alpha]^{28}{ }_{\mathrm{D}}-306.7^{\circ}\left(c 0.21, \mathrm{CHCl}_{3}\right)$; HRFAB-MS found $m / z 547.1337[\mathrm{M}+\mathrm{H}]^{+}$, calcd $m / z 547.1352$ for $\mathrm{C}_{28} \mathrm{H}_{23} \mathrm{~N}_{2} \mathrm{O}_{10} ;$ FAB-MS $m / z 547[\mathrm{M}+\mathrm{H}]^{+}, m / z 546$ [M]; UV $\lambda_{\max }{ }^{\mathrm{MeOH}}(\varepsilon) 261.5$ (26,200), $364.5(8,800) \mathrm{nm}$; IR $v_{\max }{ }^{\mathrm{KBr}} 3468,1712,1681,1637,1602$, $1508,1429,1399,1338,1278,1223,1178,1117,1019,819,760,741 \mathrm{~cm}^{-1}$; Soluble in chloroform, dimethyl sulfoxide. 


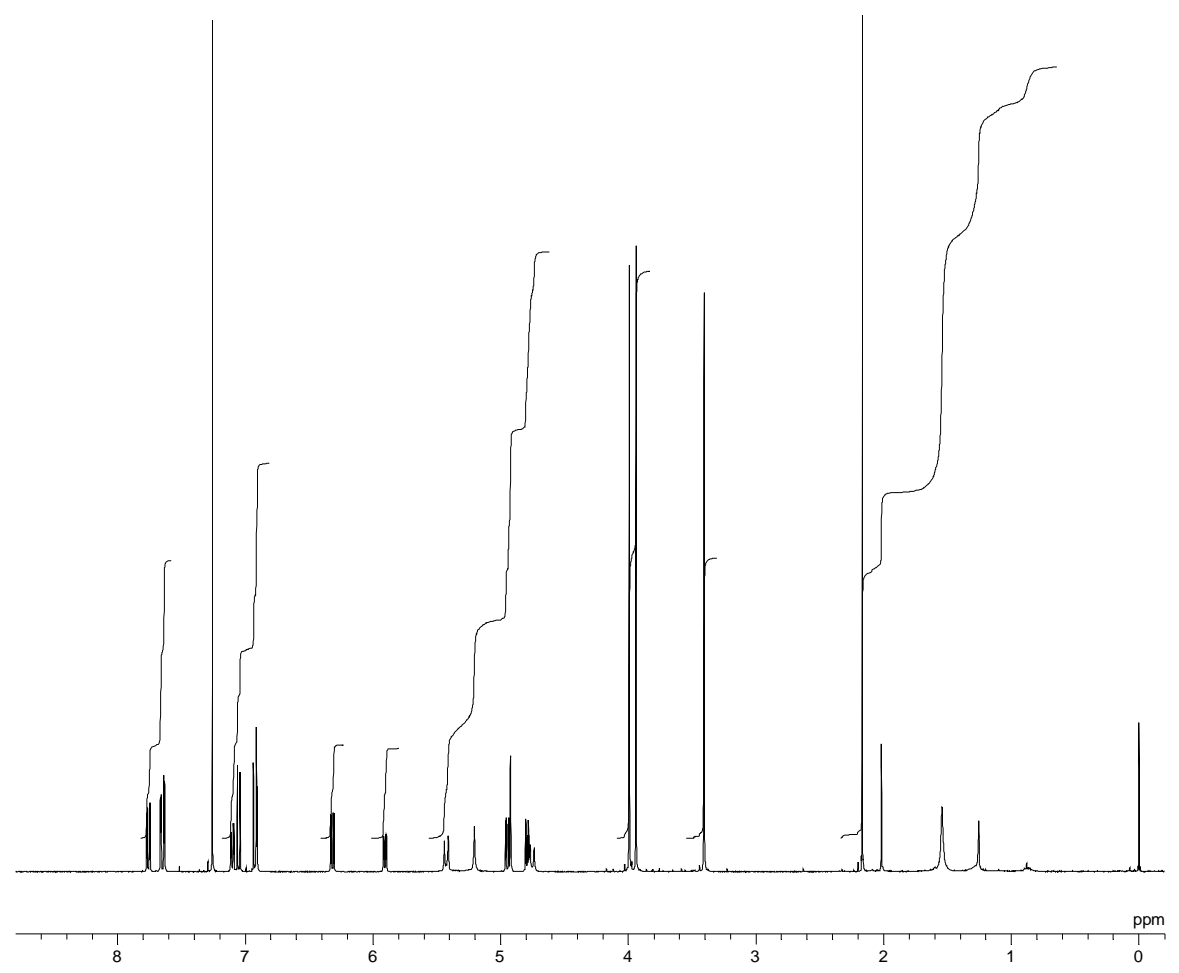

Figure 3S. ${ }^{1} \mathrm{H}$ NMR spectrum of MPC1001 (1, $\left.\mathrm{CDCl}_{3}, 400 \mathrm{MHz}\right)$.

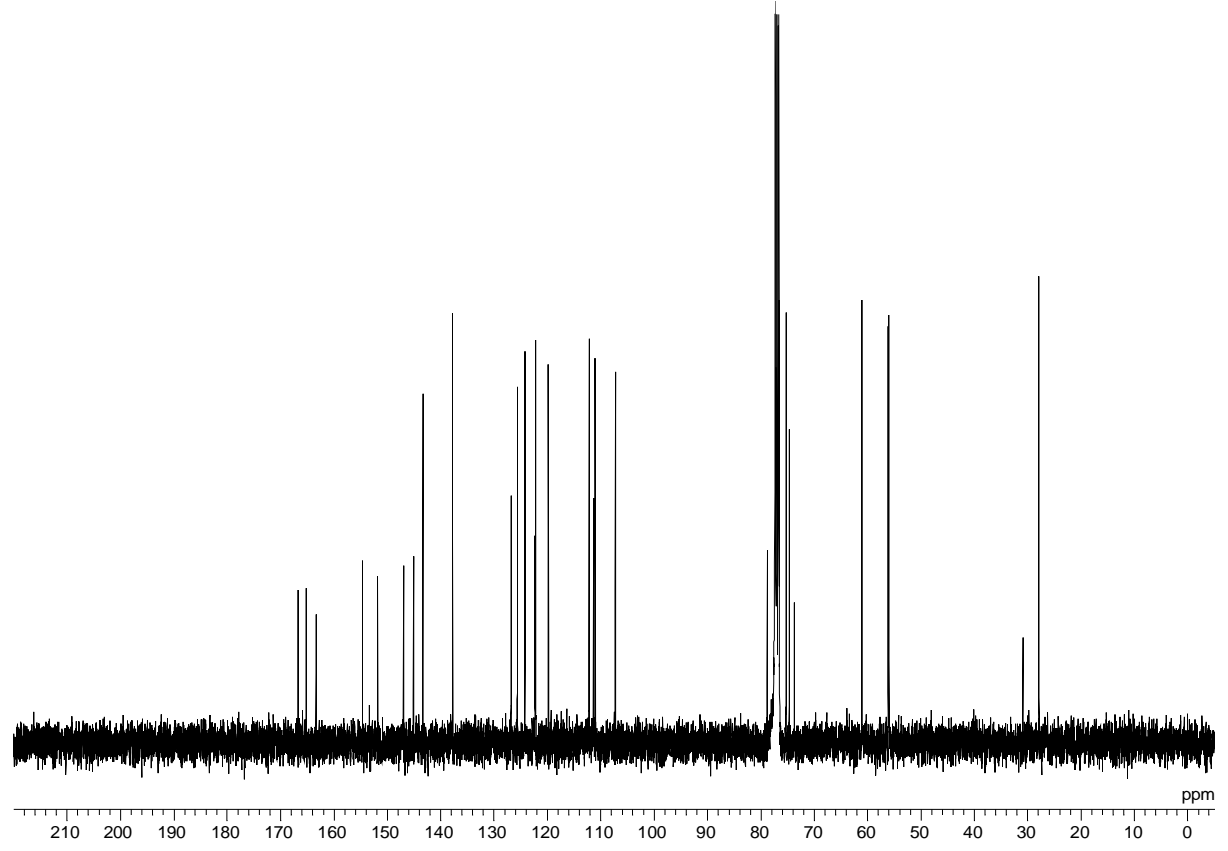

Figure 4S. ${ }^{15} \mathrm{C}$ NMR spectrum of MPC1001 (1, $\left.\mathrm{CDCl}_{3}, 100 \mathrm{MHz}\right)$. 


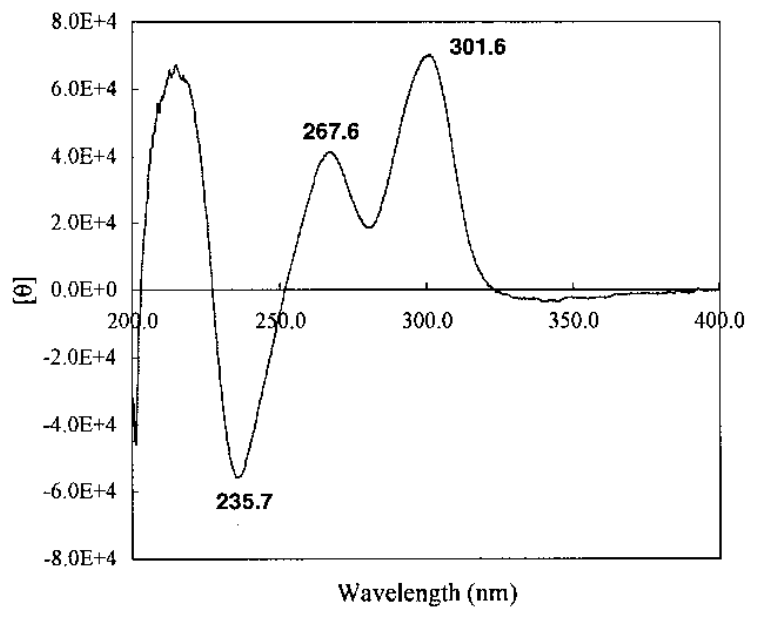

\section{MPC1001}

$[\theta]_{235.7}-5.59 \times 10^{4}$

$[\theta]_{267.6}+4.14 \times 10^{4}$

$[\theta]_{301.0}+7.01 \times 10^{4}$

$[\theta]_{340.6}-3.69 \times 10^{3}$

Measurement parameters

Blank : $\mathrm{MeOH}$

Cell : $1 \mathrm{~cm}(1 \mathrm{~mL})$

Sense : $2 \mathrm{~m}$ degree/cm

Scan : $20 \mathrm{~nm} / \mathrm{min}$

Acquisition : 2

\section{Emestrin}

$[\theta]_{233}-9.50 \times 10^{4}$

$[\theta]_{266}+6.24 \times 10^{4}$

$[\theta]_{301}+9.32 \times 10^{4}$

$[\theta]_{338}-0.38 \times 10^{4}$

Figure 5S. Comparison of CD spectral data of MPC1001 (1) to those of emestrin. 


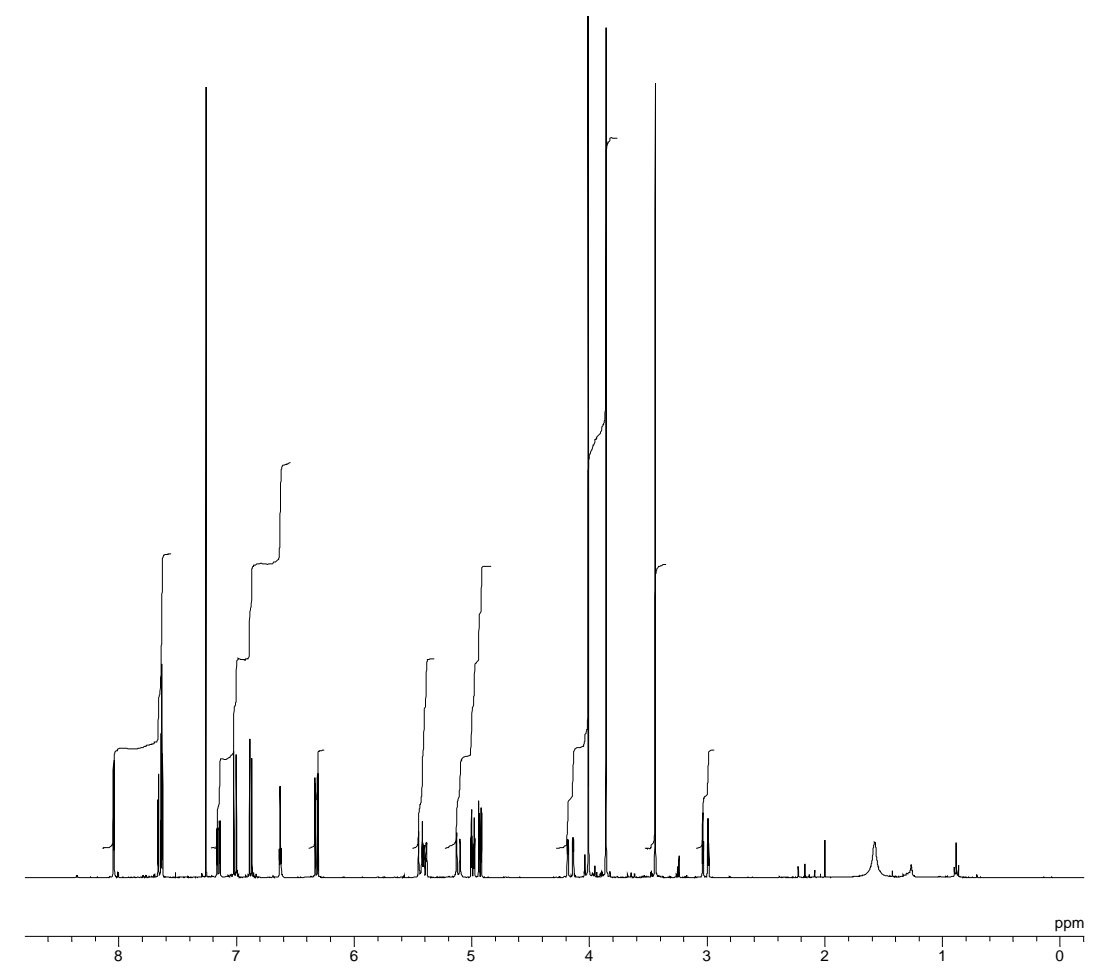

rigure 6S. ' $\mathrm{H}$ NMK spectrum of $\mathrm{MPC} 1001 \mathrm{~B}\left(2, \mathrm{CDCl}_{3}, 400 \mathrm{MHz}\right)$.
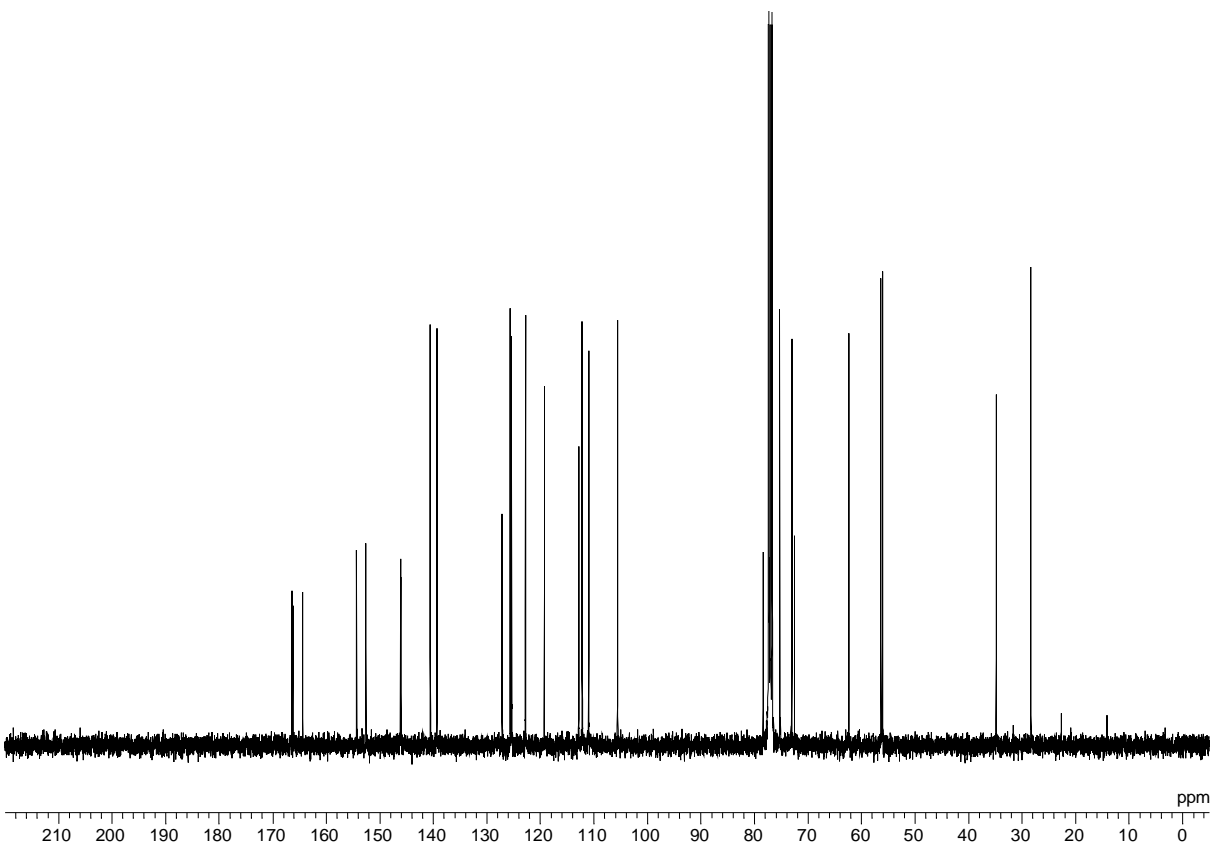

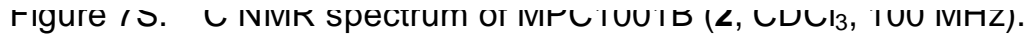




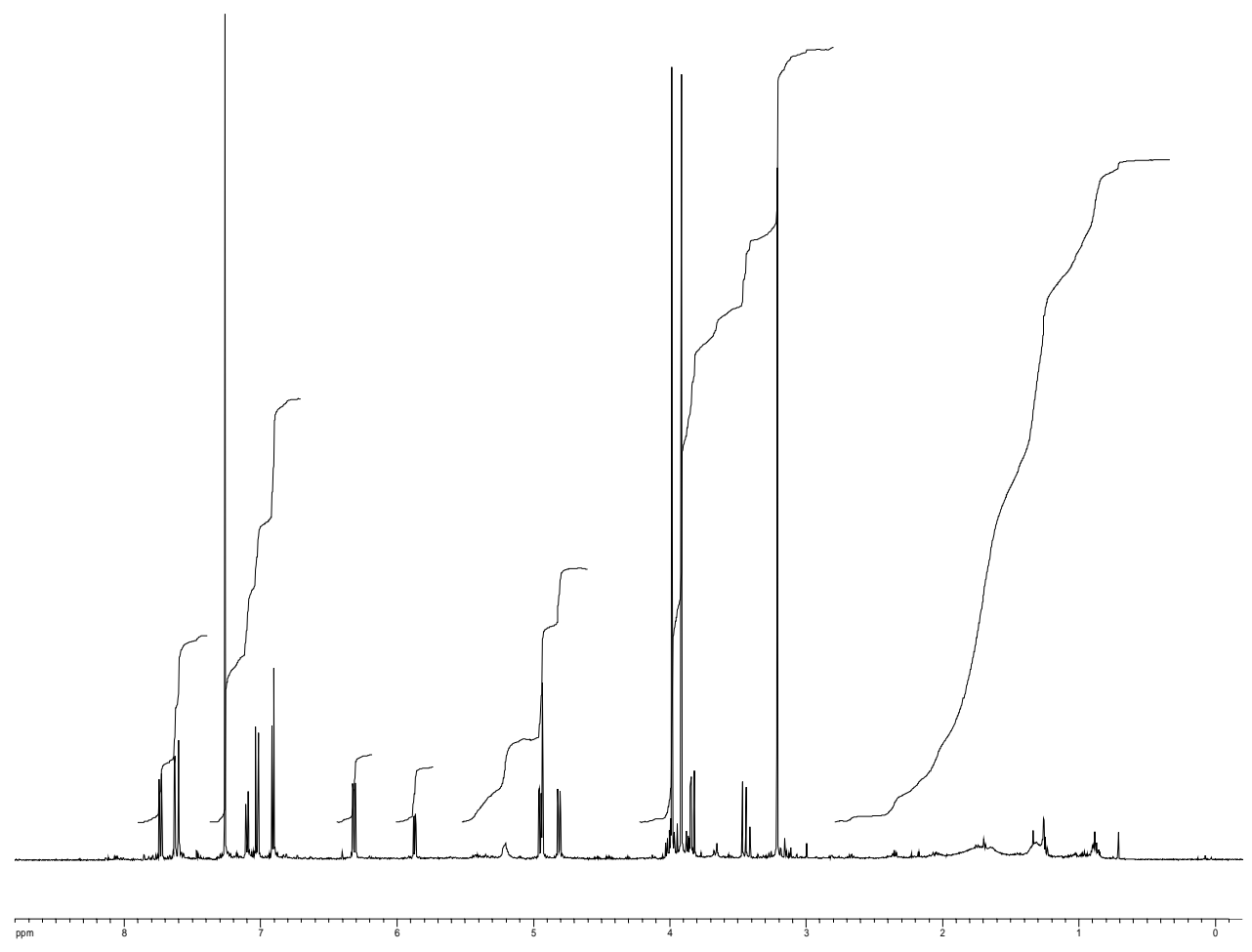

Figure 8S. ${ }^{1} \mathrm{H}$ NMR spectrum of MPC1001C (3, $\left.\mathrm{CDCl}_{3}, 500 \mathrm{MHz}\right)$.

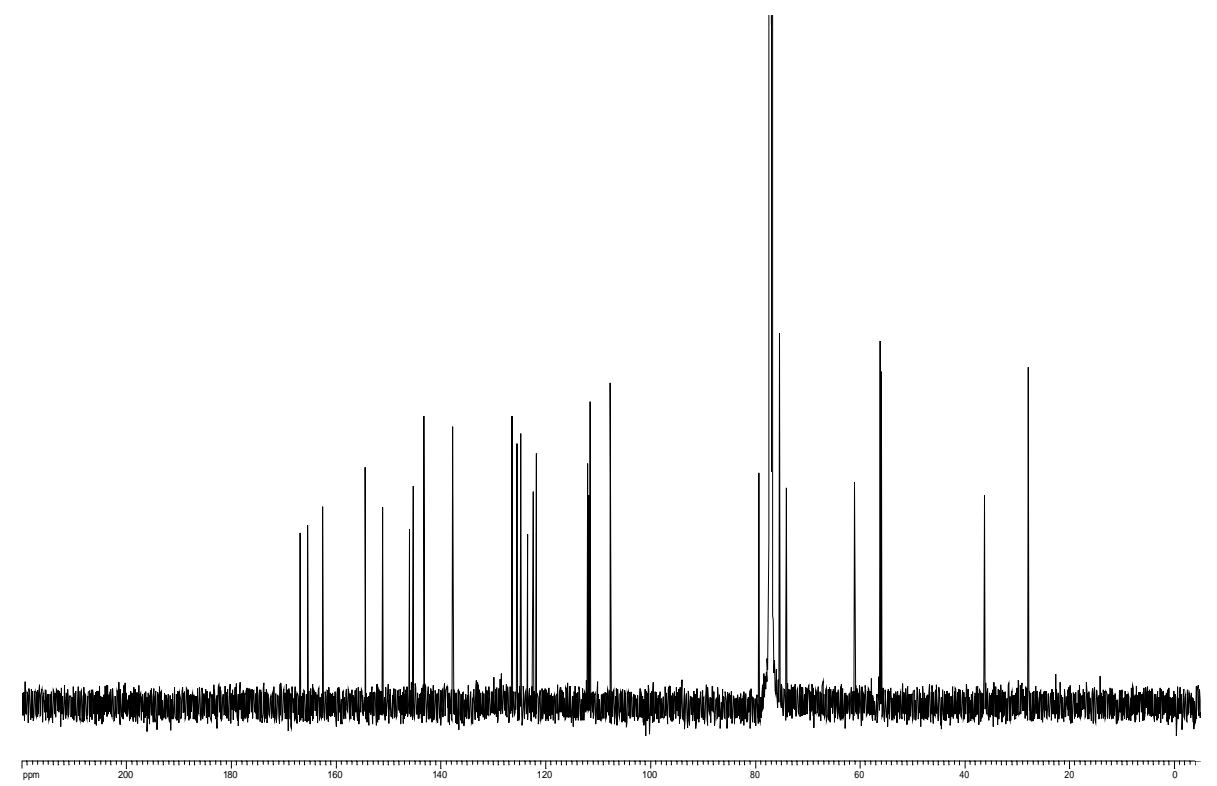

Figure 9S. ${ }^{13} \mathrm{C}$ NMR spectrum of MPC1001C $\left(3, \mathrm{CDCl}_{3}, 125 \mathrm{MHz}\right)$. 

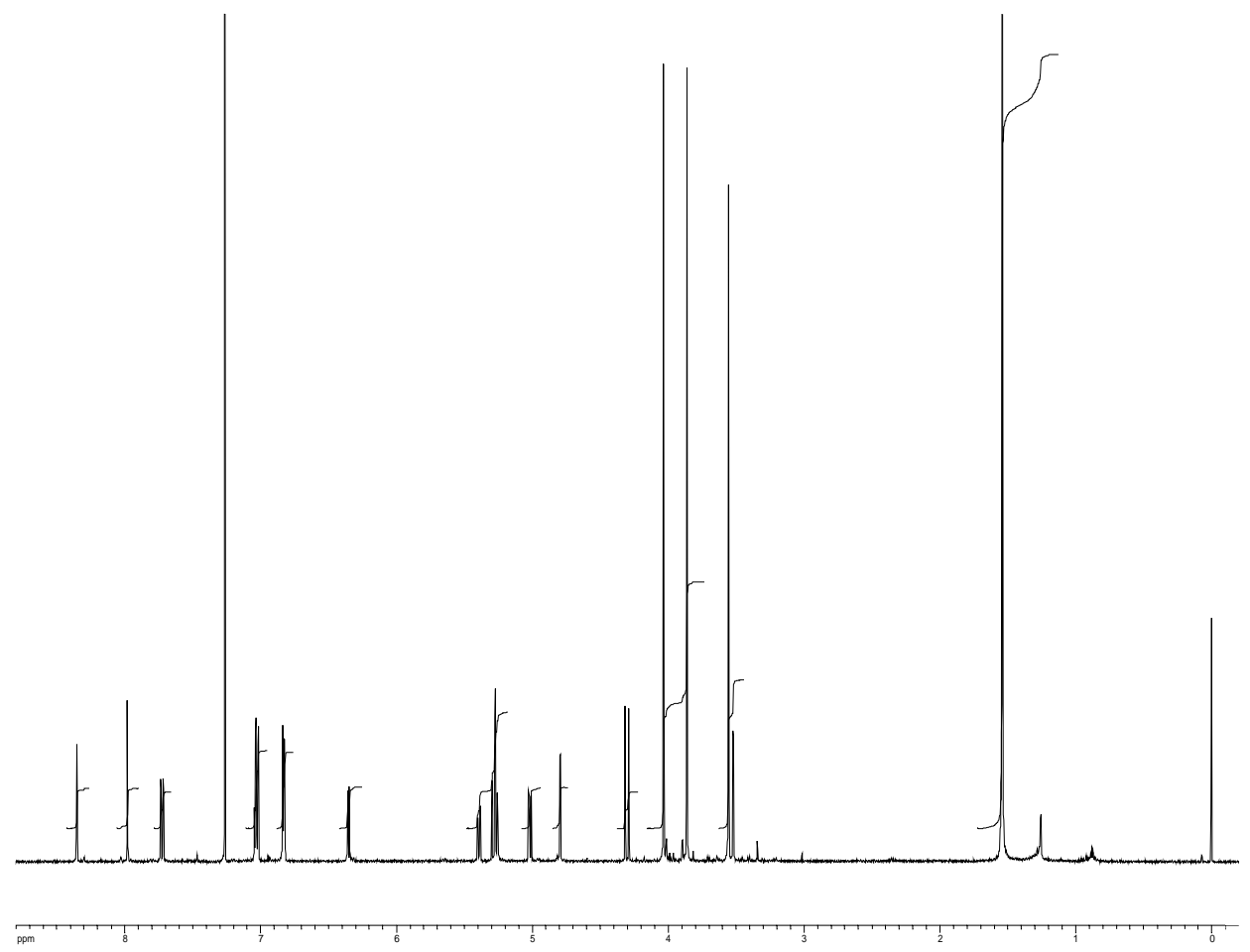

Figure 10S. ${ }^{1} \mathrm{H}$ NMR spectrum of MPC1001D $\left(4, \mathrm{CDCl}_{3}, 500 \mathrm{MHz}\right)$.

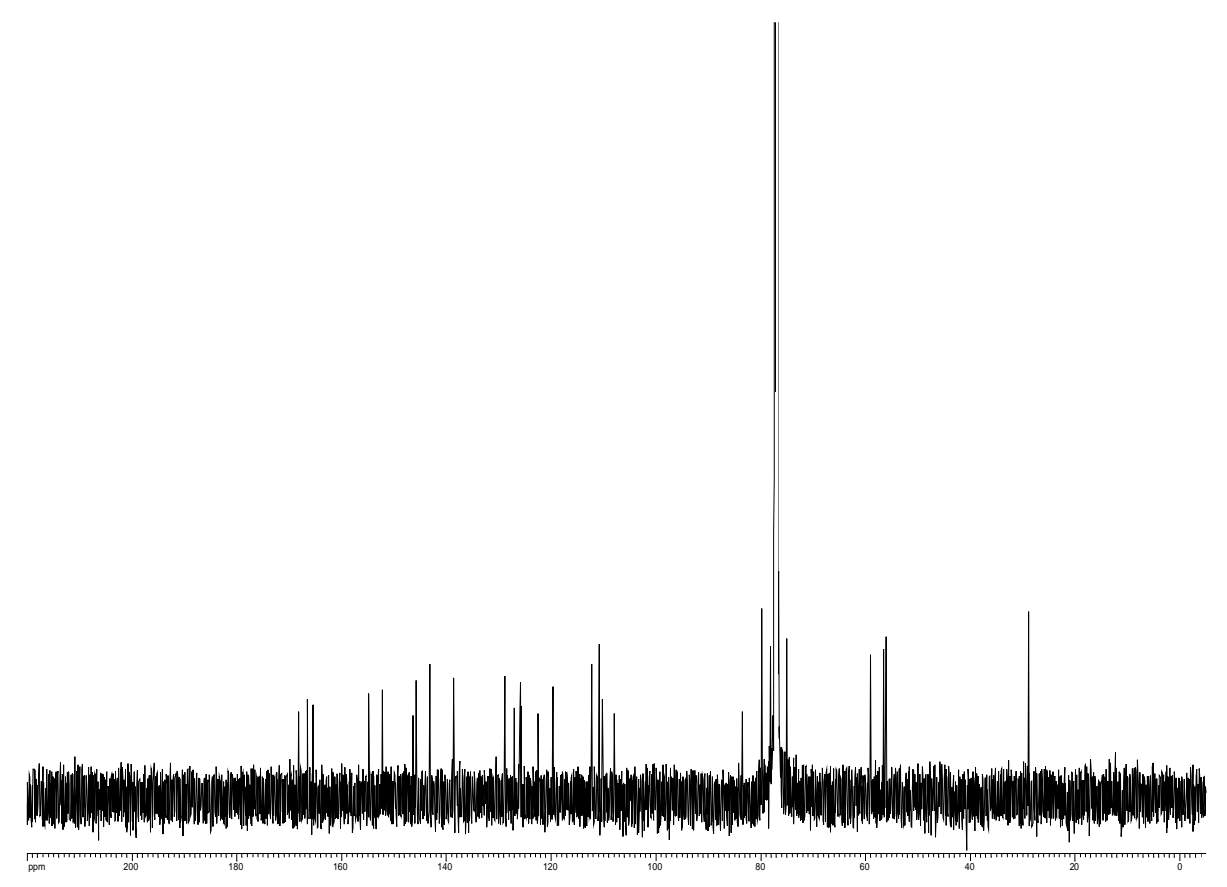

Figure 11S. ${ }^{13} \mathrm{C}$ NMR spectrum of MPC1001D (4, $\left.\mathrm{CDCl}_{3}, 125 \mathrm{MHz}\right)$. 

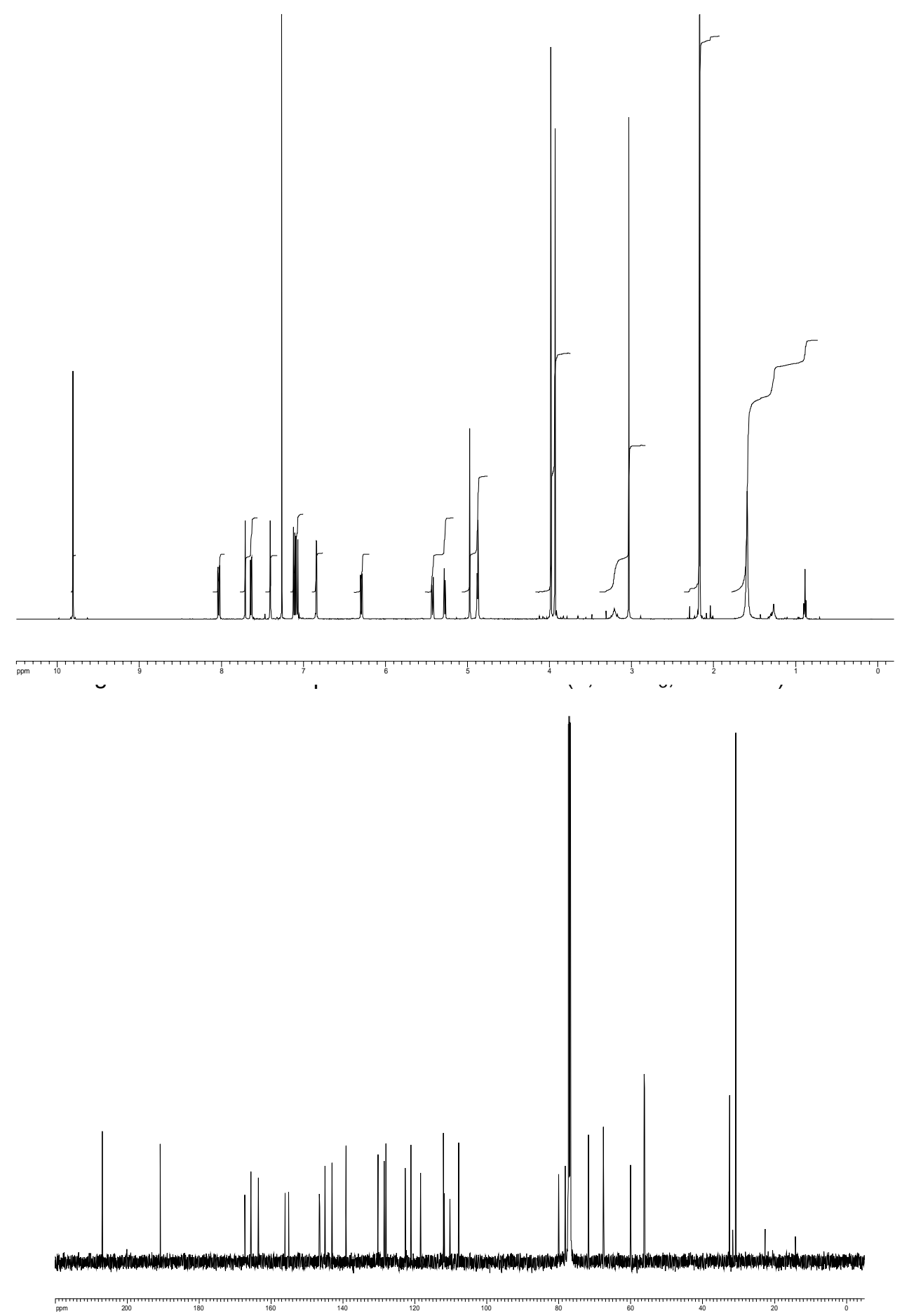

Figure $13 \mathrm{~S} .{ }^{13} \mathrm{C}$ NMR spectrum of MPC1001E $\left(5, \mathrm{CDCl}_{3}, 125 \mathrm{MHz}\right)$. 


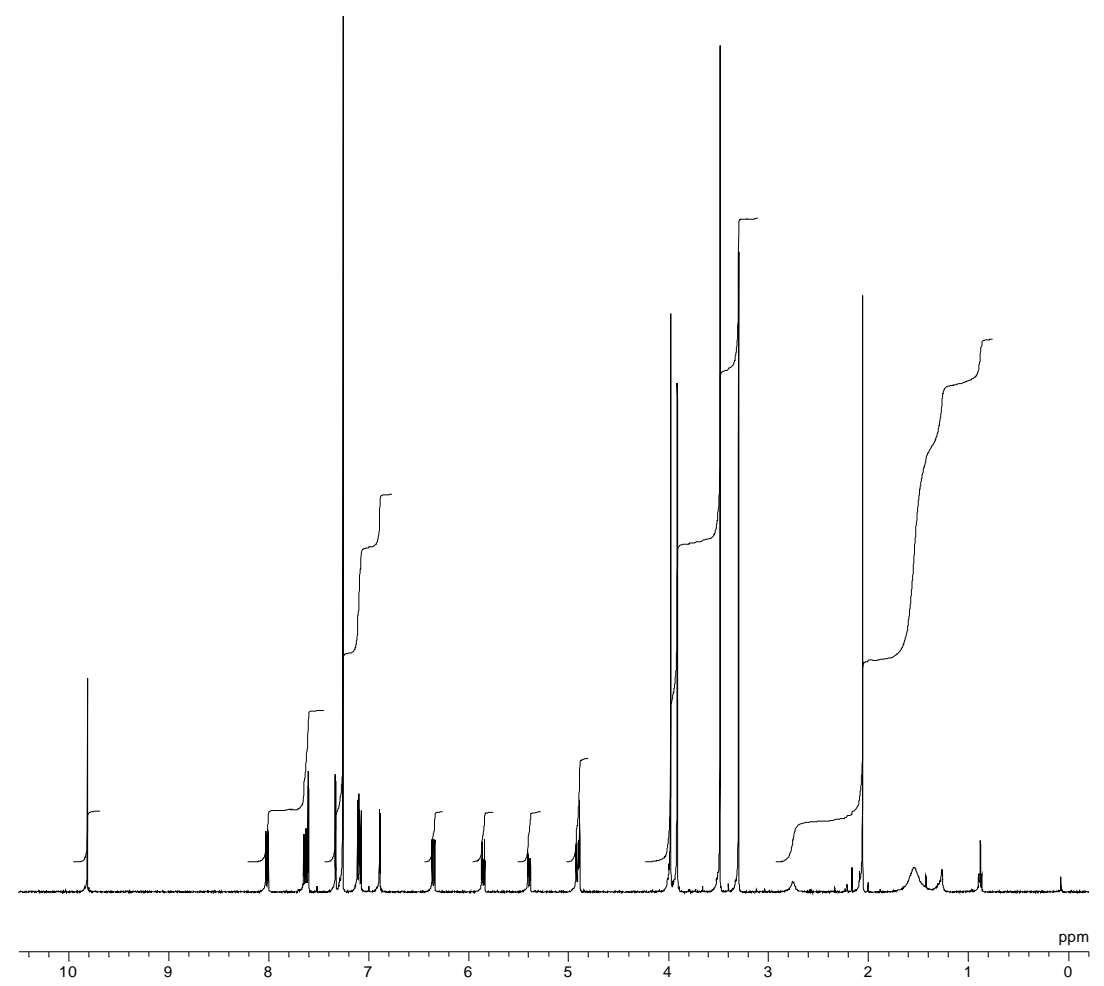

Figure $14 \mathrm{~S} .{ }^{1} \mathrm{H}$ NMR spectrum of MPC1001F $\left(6, \mathrm{CDCl}_{3}, 400 \mathrm{MHz}\right)$.

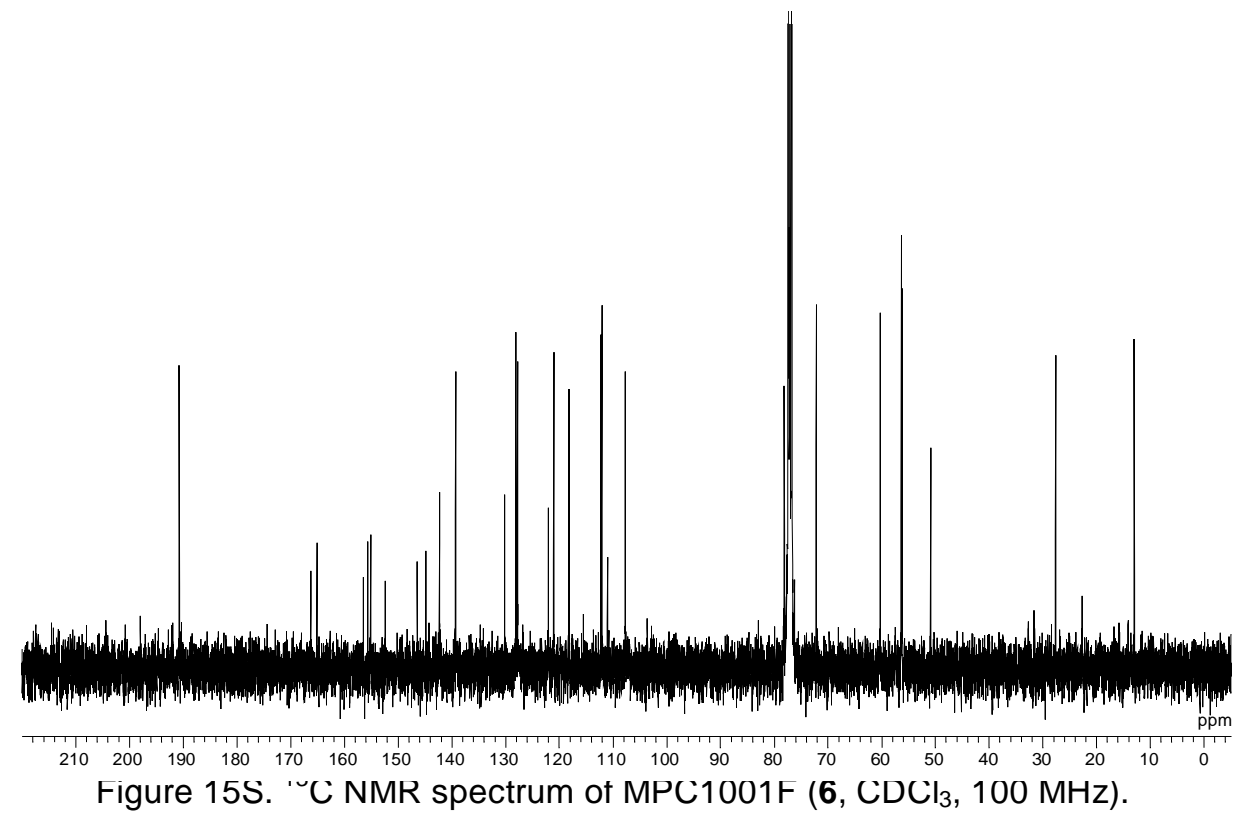




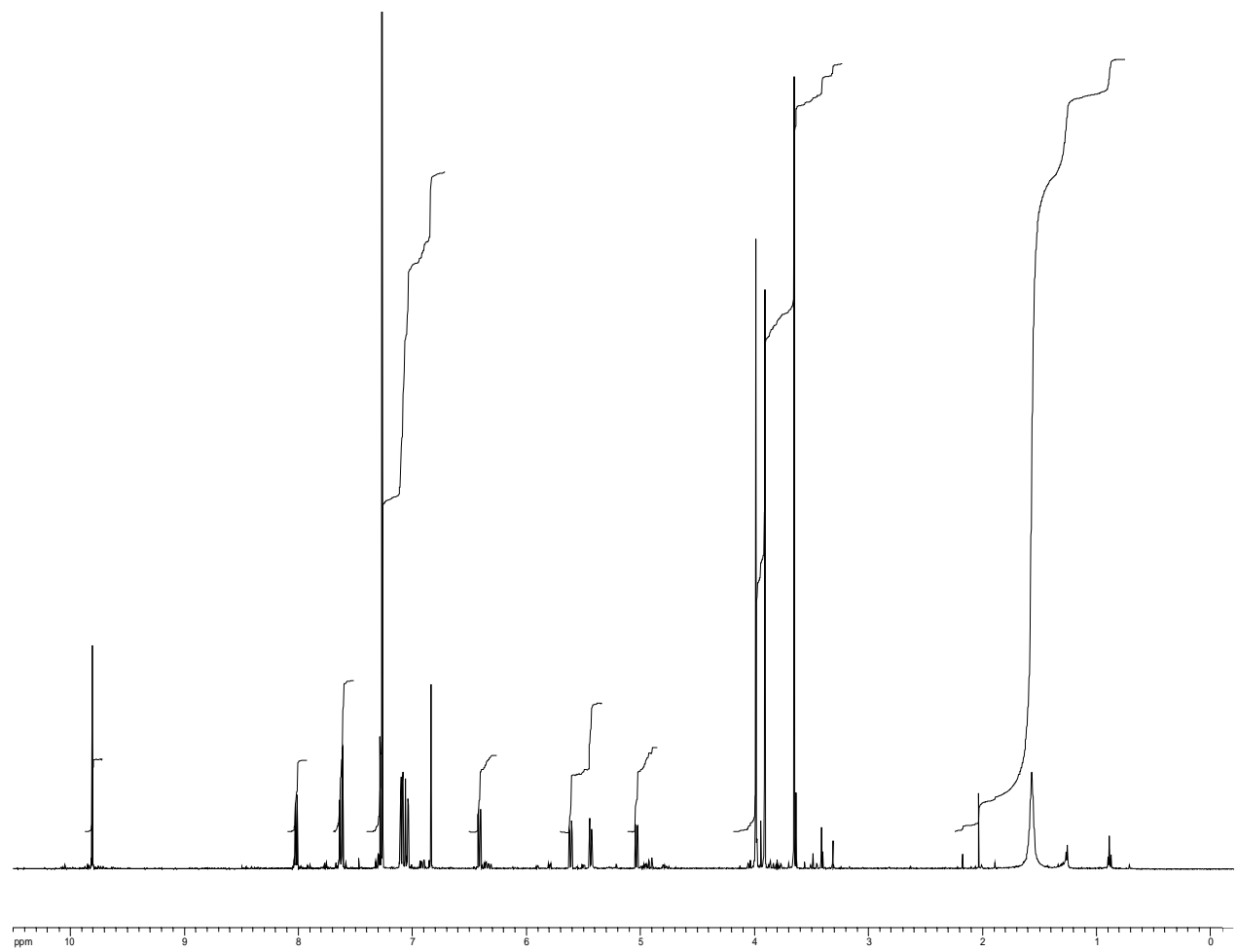

Figure 16S. ${ }^{1} \mathrm{H}$ NMR spectrum of MPC1001G (7, $\left.\mathrm{CDCl}_{3}, 500 \mathrm{MHz}\right)$.

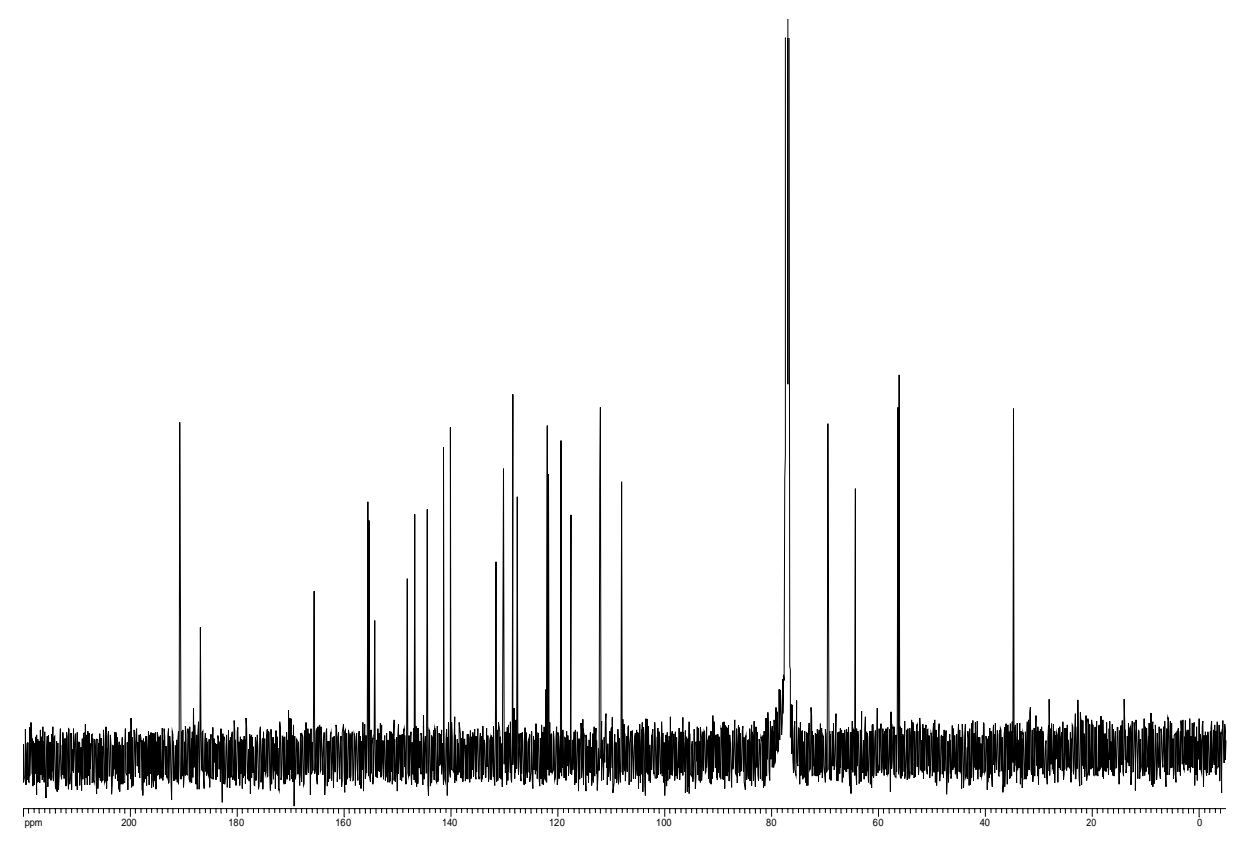

Figure 17S. ${ }^{13} \mathrm{C}$ NMR spectrum of MPC1001G $\left(7, \mathrm{CDCl}_{3}, 125 \mathrm{MHz}\right)$. 


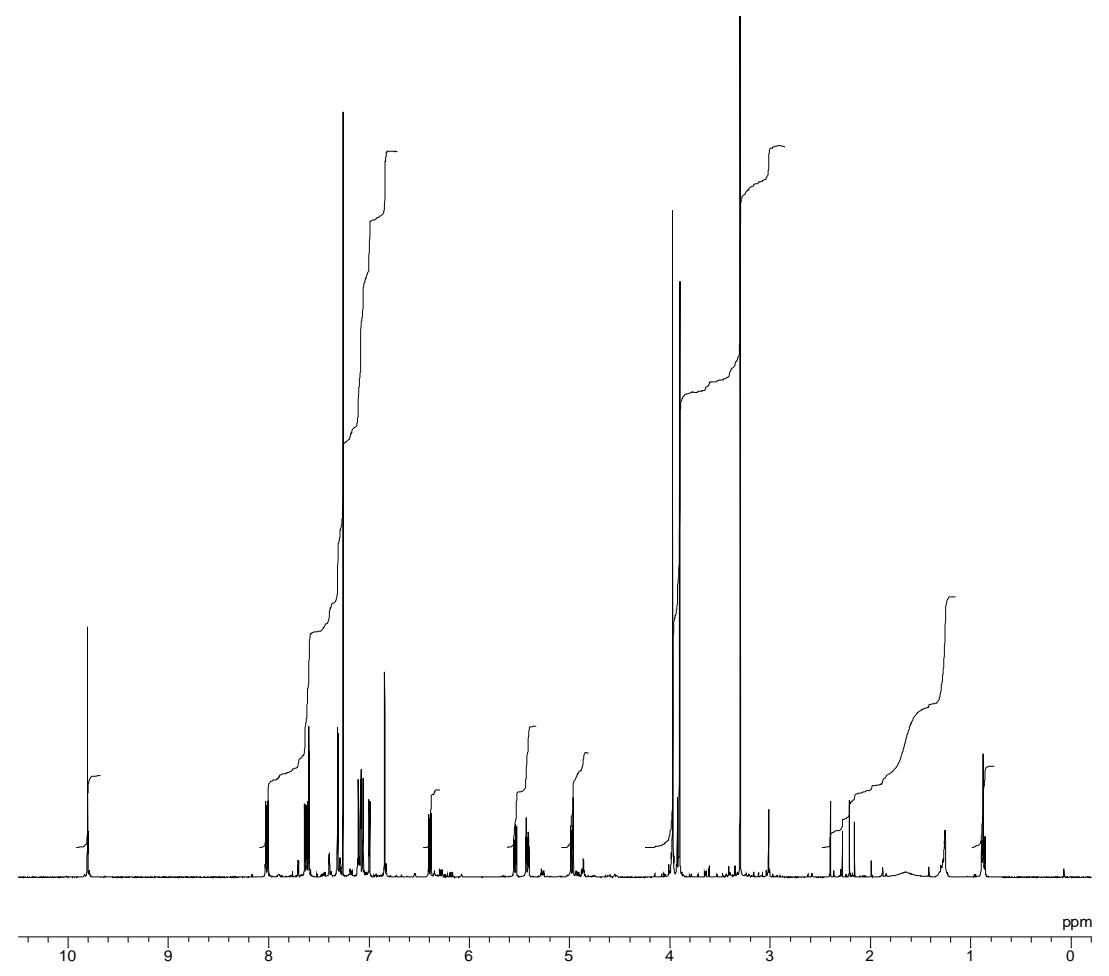

Figure 18S. ${ }^{1} \mathrm{H}$ NMR spectrum of MPC1001H (8, $\left.\mathrm{CDCl}_{3}, 400 \mathrm{MHz}\right)$.

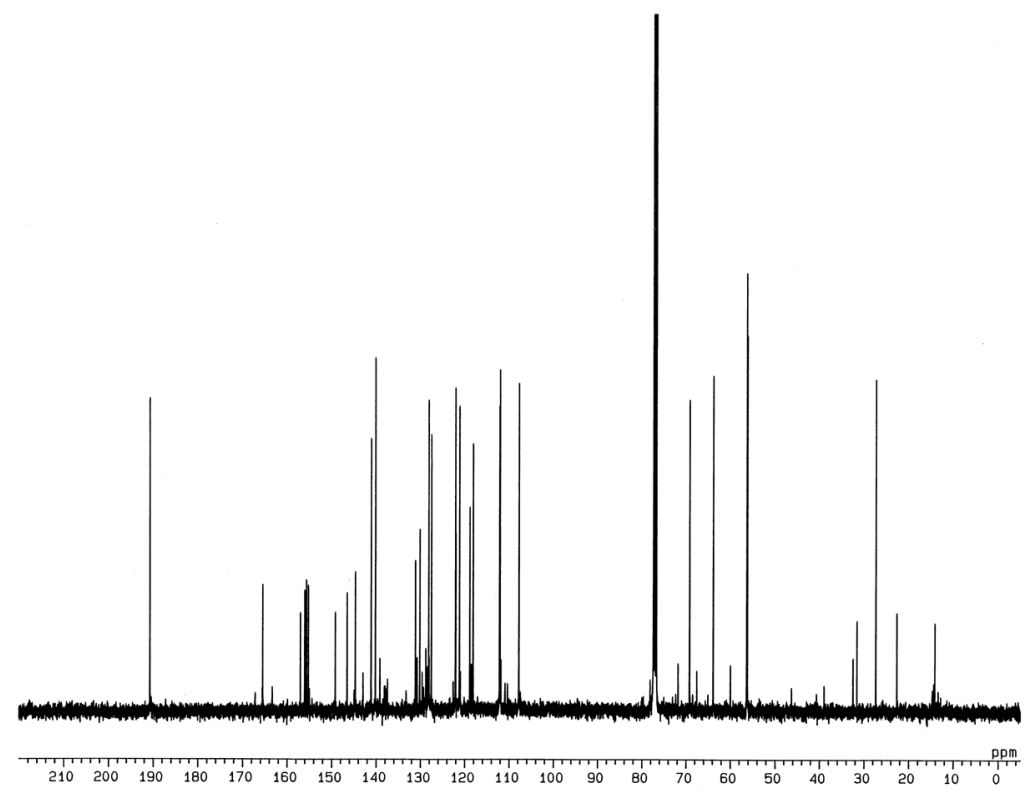

Figure 19S. ${ }^{13} \mathrm{C}$ NMR spectrum of MPC1001H (8, $\left.\mathrm{CDCl}_{3}, 100 \mathrm{MHz}\right)$. 